\title{
Evaluating two numerical advection schemes in HYCOM for eddy-resolving modelling of the Agulhas Current
}

\author{
B. C. Backeberg ${ }^{1,2,3}$, L. Bertino ${ }^{2,3}$, and J. A. Johannessen ${ }^{2,3,4}$ \\ ${ }^{1}$ Department of Oceanography, University of Cape Town, South Africa \\ ${ }^{2}$ Mohn-Sverdrup Center for Global Ocean Studies and Operational Oceanography, Norway \\ ${ }^{3}$ Nansen Environmental and Remote Sensing Center, Norway \\ ${ }^{4}$ Geophysical Institute, University of Bergen, Norway
}

Received: 12 January 2009 - Published in Ocean Sci. Discuss.: 27 February 2009

Revised: 30 April 2009 - Accepted: 13 May 2009 - Published: 2 June 2009

\begin{abstract}
A 4th order advection scheme is applied in a nested eddy-resolving Hybrid Coordinate Ocean Model (HYCOM) of the greater Agulhas Current system for the purpose of testing advanced numerics as a means for improving the model simulation for eventual operational implementation. Model validation techniques comparing sea surface height variations, sea level skewness and variogram analyses to satellite altimetry measurements quantify that generally the 4th order advection scheme improves the realism of the model simulation. The most striking improvement over the standard 2nd order momentum advection scheme, is that the southern Agulhas Current is simulated as a well-defined meandering current, rather than a train of successive eddies. A better vertical structure and stronger poleward transports in the Agulhas Current core contribute toward a better southwestward penetration of the current, and its temperature field, implying a stronger Indo-Atlantic inter-ocean exchange. It is found that the transport, and hence this exchange, is sensitive to the occurrences of mesoscale features originating upstream in the Mozambique Channel and southern East Madagascar Current, and that the improved HYCOM simulation is well suited for further studies of these inter-actions.
\end{abstract}

\section{Introduction}

Modelling of the greater Agulhas Current regime, in particular of the very energetic retroflection region, is challenging. Ocean circulation models usually simulate the southern Agulhas Current as a train of large eddies extending from the Agulhas Plateau to the retroflection, rather than a continuous, well-defined current

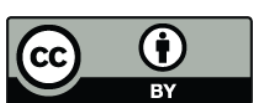

Correspondence to: B. C. Backeberg

(bjorn.backeberg@nersc.no) (e.g. Barnier et al., 2006; Backeberg et al., 2008). Consequently the simulated dynamics in the retroflection area with the periodic shedding of Agulhas Rings and maintenance of the return flow may be hampered.

Advances in model development, combined with more adequate model validation is necessary to limit this deficiency. In essence there are three ways in which ocean models can be improved (Bleck, 2006), notably by: increasing the model resolution, incorporating better model physics and implementing more adequate model numerics. Increasing the grid resolution would, in theory, allow the numerical solution to resolve finer scales. But at the border between resolved and unresolved scales of motion, the interaction of physical processes needs to be parameterised, and therefore truncation errors continue to be problematic. Improving the model physics implies better parameterisation of the physical processes which are not resolved in the model grid. Improving the model numerics, as with higher grid resolution, would lower the truncation error of the finite difference scheme used in the ocean model.

There are several ways in which model numerics can be improved. One approach is to transform the finite difference equations into a coordinate system so that they become easier to solve, and as a result the accuracy of the solutions may be improved. This approach has been adopted in isopycnic coordinate models such as the Miami Isopycnic Coordinate Ocean Model (MICOM; Bleck and Smith, 1990). In the case of isopycnic coordinate models, potential density has become the independent variable, instead of depth, which is used in Cartesian coordinate models. The advantage of using potential density as the vertical coordinate is that adiabatic flow, which is 3-D in Cartesian space, becomes 2-D in potential density space. This makes it easier to satisfy adiabatic constraints of temperature and salinity when estimating their lateral flow. There are two main disadvantages of having potential density as the vertical coordinate.

Published by Copernicus Publications on behalf of the European Geosciences Union. 
Firstly, what is known as the outcropping problem, isopycnic coordinate surfaces intersect the sea surface and secondly, there is a lack of vertical resolution when simulating unstratified water columns. The Hybrid Coordinate Ocean Model (HYCOM; Bleck, 2002) was developed to combat these problems. It does so by reverting to fixed-depth (z-level or bottom-following) coordinates in unstratified waters, and when outcropping occurs, the layer thickness tends to zero but remains isopycnal in nature.

Model numerics may also be improved by applying higher-order finite difference approximations. This would reduce the truncation error, much like increasing the model grid resolution, but at a lower computational cost (Sanderson, 1998). One such scheme is the quadratic upstream interpolation for convective kinematics (QUICK; Leonard, 1979). It was shown that implementing the QUICK scheme in realistic applications of ocean models generally improves their realism (Webb et al., 1998). In particular, in a case study for the Agulhas Current, where the QUICK scheme was applied to both tracer and momentum advection, the narrow, warm Agulhas Current core was significantly improved, resulting in a much better southwestward penetration of the temperature field, a deficiency noted in an application of HYCOM to the greater Agulhas Current system (Backeberg et al., 2008).

Depending on the process of interest, it is not necessary to approximate all terms to the higher-order (Sanderson, 1998). Studies have shown that applying the 4th order scheme only to momentum advection improves the potential vorticity dynamics and conservation (e.g. Morel et al., 2006; Winther et al., 2007). Winther et al. (2007) conclude that with model grid spacing which is smaller than the Rossby radius of deformation, higher-order approximation need only be applied to the momentum scheme in order to yield beneficial results. Moreover, this is achieved at a fraction of the computational cost of increasing the grid resolution. An application of HY$\mathrm{COM}$ for the Agulhas Current has been thoroughly evaluated in Backeberg et al. (2008). It was concluded that the simulation, using a second order momentum advection scheme, provided an adequate representation of the general circulation and mesoscale variability for the region, although some inaccuracies were recognised. Notably, a train of eddies extending from the Agulhas Plateau to the retroflection, instead of a well-defined current core.

In light of improving the model numerics, the QUICK scheme, with the bi-harmonic viscosity modified to minimise the viscosity coefficient (as in Winther et al., 2007), was applied to momentum advection in the Agulhas HYCOM. This 4th order scheme (hereafter referred to as O4) is compared to the 2 nd order advection scheme (hereafter referred to as O2). A similar study using a high resolution model of the North Sea is documented in Winther et al. (2007). In the Agulhas Current, the regular availability of data, in particular satellite altimetry data, supports a more detailed statistical study, using skewness and spatial variograms. Although these statistical tools are very simple and classical, their use in oceanography is still marginal. We will show that they are selective tests for model validation.

Applying and validating model improvements provides a better quantitative understanding of the role and influence of mesoscale variability and dynamics in the Agulhas Current and hence the retroflection region with its frequency of eddy shedding is obtained. Advancing the knowledge of this mesoscale variability and dynamics will in turn yield better grounds for model validation, which is essential in order to gradually progress towards establishing and implementing an operational monitoring and forecasting system for the greater Agulhas Current regime.

A description of the observations and model is outlined in Sect. 2, followed by a qualitative assessment of the two simulation experiments (Sect. 3). Mesoscale variability is studied in both simulations (Sect. 4), and compared to satellite altimetry measurements considering sea surface height variations (Sect. 4.1), sea level skewness (Sect. 4.2) and variogram analyses (Sect. 4.3). The main findings of the intercomparisons are summarised in the conclusion.

\section{Description of observations and model}

\subsection{Satellite altimetry}

The satellite altimetry data is a very important global data set for ocean circulation studies as well as validation of models. It spans a period of more than 15 years and provides measurements of sea surface height variations or sea level anomalies (SLA) at a spatial and temporal scale of about $40 \mathrm{~km}$ and 7 days. This is adequate for the Agulhas Current, where the mesoscale signals are very distinct.

The absolute dynamic topography is the sum of SLA and the mean dynamic topography from Rio 05 (Rio and Hernandez, 2004; Rio et al., 2005). These data are available from Ssalto/Duacs and distributed by Aviso, with support from the Centre National d'Etudes Spatiales (CNES; www.aviso.oceanobs.com).

Recently Aviso has developed better algorithms for data retrieval in coastal areas, where the measurement corrections are more demanding. This is very valuable for studies of the Agulhas Current, which flows very close to the coast between $30-34^{\circ} \mathrm{S}$.

\subsection{Sea surface temperatures (SSTs)}

Reynolds SSTs (Reynolds et al., 2002) are produced weekly on a one degree grid by the Climate Diagnostic Centre. The data are optimally interpolated, incorporating in situ and satellite SSTs and are adjusted for sea-ice cover. Before the analysis the satellite data are bias-corrected using the method described in Reynolds (1988) and Reynolds and Marsico (1994). 
The Reynolds SST data is provided by the NOAA/OAR/ESRL PSD, Boulder, Colorado, USA, and is available freely from their Web site at www.cdc.noaa.gov.

More recently, with the launch of NASA's AQUA satellite, higher resolution $(\sim 25 \mathrm{~km})$ near-global SST data have become available on a daily basis. These are obtained by interpolating SST measurements from the Tropical Rainfall Measuring Mission (TRMM) Microwave Imager (TMI) and the Advanced Microwave Scanning Radiometer for EOS (AMSR-E, onboard AQUA). For these sensors, missing data only occurs in regions near land or where they are influenced by sun-glitter and rain. Although these microwave SST products (hereafter referred to as MW SST) have a lower spatial resolution than full SST measurements from infrared sensors, they represent a significant improvement over the widely used weekly, one degree $(\sim 100 \mathrm{~km})$ NCEP OI (Reynolds) SST product.

Microwave OI SST data are produced by Remote Sensing Systems and sponsored by National Oceanographic Partnership Program (NOPP), the NASA Earth Science Physical Oceanography Program, and the NASA REASON DISCOVER Project. The MW SSTs are available at www.remss.com.

\subsection{Hybrid coordinate ocean model (HYCOM)}

The Hybrid Coordinate Ocean Model (HYCOM) is a primitive equation model, that combines the optimal features of isopycnic-coordinate and fixed-grid ocean circulation models within one framework (Bleck, 2002).

At each time-step HYCOM determines an optimal hybrid layer distribution, interchanging between isopycnic $(\rho)$ vertical coordinates when simulating the stratified open ocean, z-level coordinates when resolving upper-ocean mixed layer dynamic processes and $\sigma$-coordinates in the shallow coastal regions. During these vertical coordinate interchanges, emphasis is placed on restoring the grid to isopycnic coordinates.

The HYCOM system set up to simulate the Agulhas Current system involves two models: a coarse resolution, basinscale model of the Indian and Southern Oceans, which provides boundary conditions for a regional nested highresolution model of the Agulhas Current system (Fig. 1).

The model grids were created using the conformal mapping tool developed by Bentsen et al. (1999). Realistic ocean bathymetry data, from the 1' resolution General Bathymetric Chart of the Oceans (GEBCO; www.ngdc.noaa.gov/mgg/gebco) was interpolated to each of the model grids.

A $\frac{1}{10}$ th of a degree model of the Agulhas Current system (AGULHAS) receives boundary conditions from the coarser model (INDIA) in a one way nesting approach. For the slow varying variables such as baroclinic velocity, temperature, salinity and layer interfaces, the boundary condition calculations are based on the flow relaxation scheme

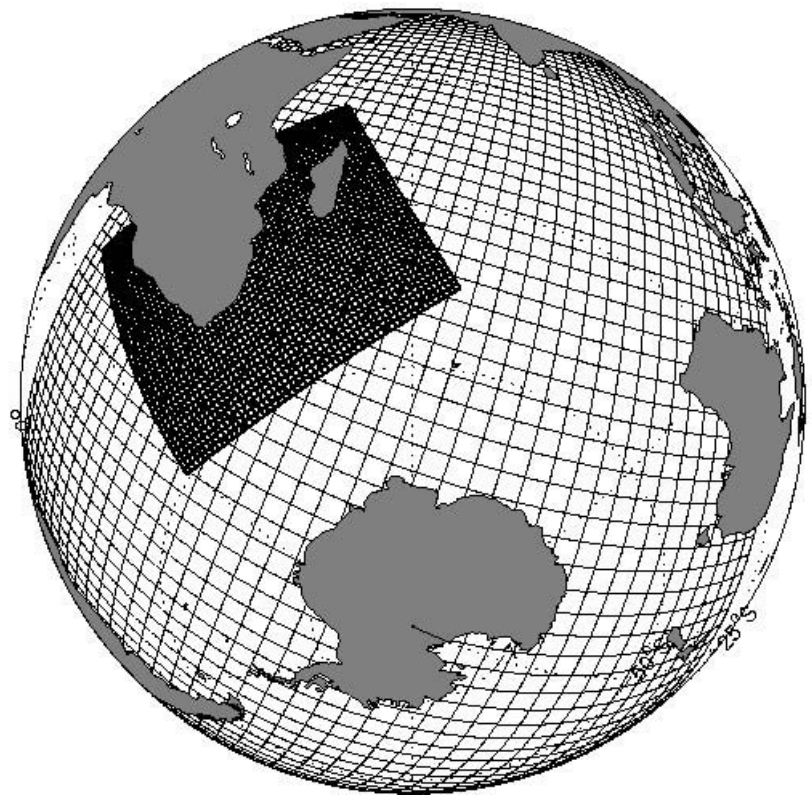

Fig. 1. Illustration of the HYCOM model system: coarse resolution basin-scale (INDIA) model grid, provides boundary conditions for a high-resolution nested regional (AGULHAS) model grid. Every 10th grid cell was plotted to produce the mesh grid.

(FRS; Davies, 1983). The barotropic variables are treated in a hyperbolic wave equation for pressure and vertically integrated velocities (Browning and Kreiss, 1982, 1986).

The geographical domain of AGULHAS extends from $0^{\circ}$ $60^{\circ} \mathrm{E}$ and from $10^{\circ}-50^{\circ} \mathrm{S}$, to include the major features of the Agulhas Current system, namely the source regions, the Mozambique Channel and the East Madagascar Current, the Agulhas Current proper, the Agulhas Retroflection, the ring shedding corridor and the Agulhas Return Current.

The vertical discretisation in AGULHAS mimics that of INDIA. It has 30 hybrid layers with target densities ranging from 21.0 to 28.3 , referenced to $\sigma_{0}$.

INDIA was initialised from Generalised Digital Environmental Model (GDEM; Teague et al., 1990) data, and a spinup period of 8 years using monthly mean climatological forcing was run to allow it to reach a balanced state prior to beginning the simulation experiments. The forcing data used during the spin-up period is based on the ERA40 re-analysis (Uppala et al., 2005), with a correction applied to dampen the strong precipitation bias of the ERA40 re-analysis in the tropical oceans.

AGULHAS was initialised from a balanced INDIA field interpolated to the high resolution grid.

Two simulation experiments of the nested high resolution model are discussed in this paper. The $\mathrm{O} 2$ experiment uses the standard 2nd order advection scheme, while in the $\mathrm{O} 4$ experiment a 4th order advection scheme based on the QUICK scheme (Leonard, 1979), with the bi-harmonic 
Table 1. Values and explanations of parameters chosen for the two simulation experiments.

\begin{tabular}{cccl}
\hline Parameter & O2 & O4 & Explanation \\
\hline slip & -1 & -1 & +1 for free-slip, -1 for non-slip boundary conditions \\
visco2 & 0.10 & 0.07 & deformation-dependent Laplacian viscosity factor \\
visco4 & 0.00 & 0.00 & deformation-dependent bi-harmonic viscosity factor \\
veldf2 & 0.03 & 0.00 & diffusion velocity $(\mathrm{m} / \mathrm{s})$ for Laplacian momentum dissipation \\
veldf4 & 0.01 & 0.00 & diffusion velocity $(\mathrm{m} / \mathrm{s})$ for bi-harmonic momentum dissipation \\
thkdf2 & 0.00 & 0.00 & diffusion velocity $(\mathrm{m} / \mathrm{s})$ for Laplacian thickness diffusion \\
thkdf4 & 0.01 & 0.00 & diffusion velocity $(\mathrm{m} / \mathrm{s})$ for bi-harmonic thickness diffusion \\
temdf2 & 0.015 & 0.005 & diffusion velocity $(\mathrm{m} / \mathrm{s})$ for Laplacian temperature/salinity diffusion \\
\hline
\end{tabular}

viscosity modified to minimise the viscosity coefficient, was applied.

Table 1 indicates the values of the parameters chosen for the two simulation experiments. The viscosity parameters have been carefully adjusted at the lowermost acceptable value. Lower viscosities in the 4th order scheme cause the model to crash, by violation of the CourantFriedrichsLewy (CFL) conditions, and in the 2nd order scheme they exhibit unphysical numerical noise.

Both simulations use the same nesting conditions, and in each case the same forcing fields were applied. Namely, synoptic atmospheric forcing fields from ERA40, before 2002 and then operational analyses from the ECMWF, with cloud cover data from the Comprehensive Ocean-Atmosphere Data Set (COADS; Slutz et al., 1985) and precipitation data from Legates and Willmott (1990).

\section{Assessment of the simulation results}

Figure 2 shows the area averaged mean kinetic energy (MKE; a) and the eddy kinetic energy (EKE; b) for the Agulhas domain.

The simulation study is carried out over a 11-year period from 1996 to 2006, inclusive. Both experiments reveal a rapid increase during the first 2-3 years in MKE (until 1998) and EKE (until 1999). After which they decrease to a stable level in the year 2001. It takes about 1 year longer for the $\mathrm{O} 2$ simulation to adjust to its stable state, which in the case of EKE is about $40 \mathrm{~cm}^{2} \mathrm{~s}^{-2}$ below, or $14 \%$ less than that of the $\mathrm{O} 4$ simulation and the observations.

Both simulations are able to reproduce the inter-annual changes in EKE from 2001 onwards, and the $\mathrm{O} 4$ experiment does so in very good agreement to the observed EKE from Aviso. The agreement with the MKE is a bit more sporadic, and both simulations underestimate the overall MKE for the region, although they are able to capture the general changes in the yearly MKE.

When nesting models in regions where strong boundary currents occur, such as the Agulhas Current, a long adjustment time seems to be needed in order to evacuate all the transient modes from the model domain. Further work is
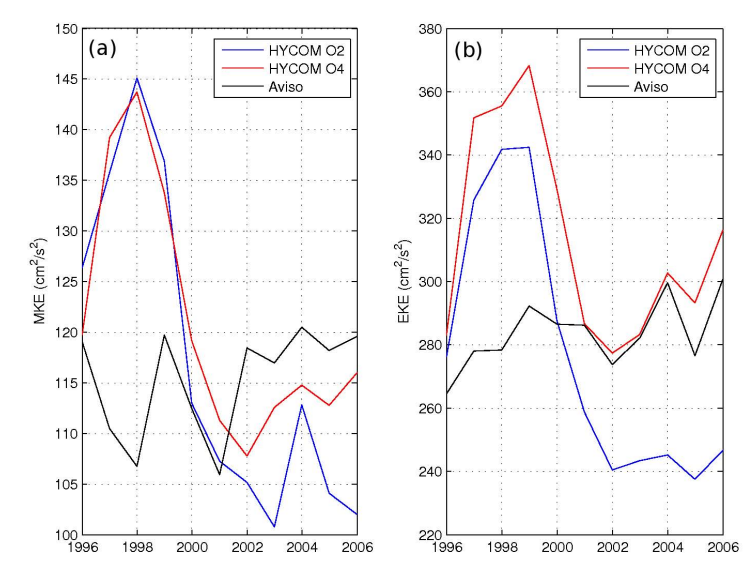

Fig. 2. Annual averages of the mean kinetic energy (a) and eddy kinetic energy (b) for the Agulhas domain. HYCOM O2 (blue), HYCOM O4 (red) and calculated from Aviso geostrophic currents (black).

needed to address this issue, but does not lie within the scope of this study. For the purposes here, the first 5 years of the simulation are considered to represent the spin-up period. Only the latter period from 2001-2006 will be used in the analysis.

\subsection{Vorticity analysis}

As mentioned, it is expected that applying the 4th order momentum advection scheme improves the potential vorticity dynamics. To highlight the changes evident in the two simulation experiments, the weekly average vorticity fields for the week of 23 April 2003 are given in Fig. 3.

Contrary to expectations, there does not seem to be a noticable change in the scale of the Mozambique Channel Eddies, and their intensity based on the weekly average field remains the same. The mesoscale variability in both model simulations will be examined in detail in the following sections. Note that in the $\mathrm{O} 2$ scheme, there is a lot of numerical noise, especially near the coast and the northern entrance to 


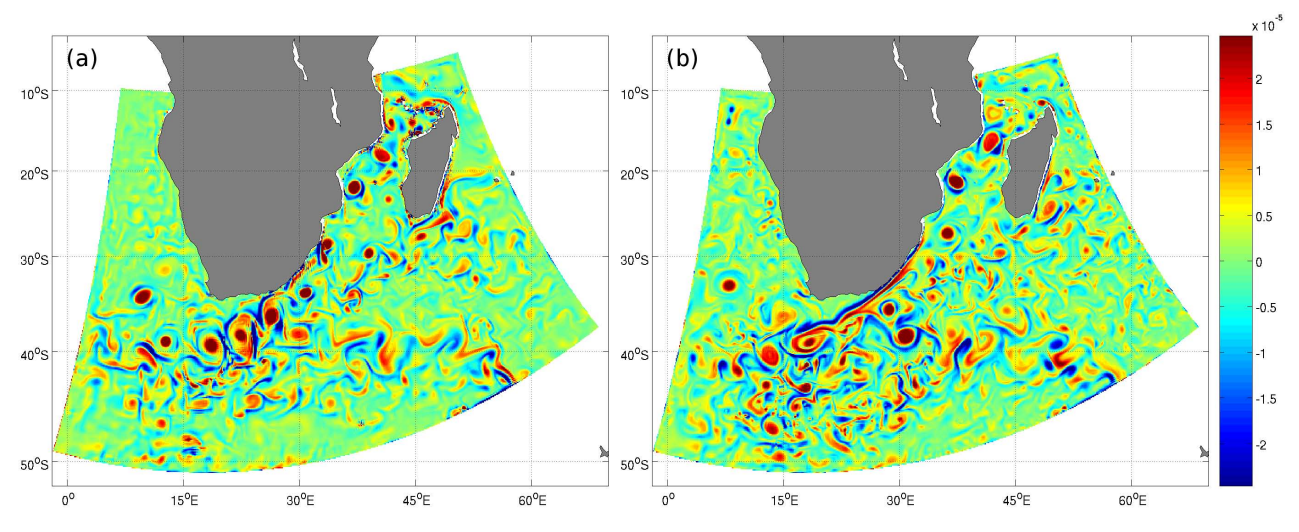

Fig. 3. Weekly average vorticity fields for the week of 23 April 2003. Derived from current velocities at $10 \mathrm{~m}$ for $\mathrm{HYCOM} \mathrm{O} 2$ (a) and HYCOM O4 (b).

the channel, around the Comoro Islands. This is ammended by applying the higher order scheme.

The most pronounced difference is evident further downstream in the northern Agulhas Current. Here the current proper can be clearly identified in the higher order scheme, while in the second order scheme it remains poorly defined, with numerical noise evident close to the coast. The extent of the Agulhas Current is defined by the stream of negative vorticity, cyclonic motion due to friction, close to the coast, with positive vorticity on its offshore side. In the $\mathrm{O} 4$ scheme, the current extends along the coast from about $27^{\circ} \mathrm{S}$ to about $34^{\circ} \mathrm{S}$, where it separates from the coast and continues southwestward toward the retroflection region near $40^{\circ} \mathrm{S}$ and $15-20^{\circ} \mathrm{E}$. As noted in Backeberg et al. (2008), the O2 scheme fails to simulate the southern Agulhas Current as well-defined meandering current, and this is highlighted in the weekly vorticity field, where a train of eddies can be seen to extend from the Agulhas Plateau (near $35^{\circ} \mathrm{S}$ and $26^{\circ} \mathrm{E}$ ) to the retroflection.

The retroflection region in the $\mathrm{O} 4$ simulation is much more chaotic, with eddies appearing to follow variable paths into the South Atlantic Ocean, a further deficiency noted of the second order scheme. Additionally, at scales smaller than the retroflection eddies, enhanced variability is evident in the the $\mathrm{O} 4$ scheme.

The most stiking improvement from applying the 4 th order advection scheme is the characterisation of the southern Agulhas Current as a well-defined meandering current and an enhancement of the mesoscale variability in particular in the retroflection region. These enhancements and their implications will be discussed in detail in the following sections.

\subsection{Mean SST distribution}

One of the deficiencies in the $\mathrm{O} 2$ model simulation was the extent of the southwestward penetration of the temperature field in the southern Agulhas Current. Webb et al. (1998) showed that by applying the QUICK scheme to both tracers and momentum a similar deficiency was improved in their simulation experiments. In these experiments with HYCOM, a 4th order scheme was only applied to momentum advection since the horizontal grid resolution is smaller than the Rossby radius of deformation, as discussed in the Introduction.

Figure 4 shows the 3 year mean SSTs (2004-2006, inclusive) from both model simulations, which are compared to the MW SST measurements described in Sect. 2.2.

The contours represent the surface expressions of the extent of the Agulhas Current $\left(20^{\circ}\right.$ and $\left.22^{\circ} \mathrm{C}\right)$ and the three main frontal regions in the Southern Ocean: the Subtropical Convergence and its northern extent (STC; $14.2^{\circ}$ and $17.9^{\circ} \mathrm{C}$ ), the Sub-Antarctic Front $\left(\mathrm{SAF} ; 7.0^{\circ} \mathrm{C}\right)$ and the Antarctic Polar Front (APF; $3.4^{\circ} \mathrm{C}$ ). The surface expressions for the frontal bands were derived from ship-board observations (Lutjeharms and Valentine, 1984).

In general, the agreement between the model and the observations is relatively good considering that no relaxation toward observed SSTs was applied in the HYCOM simulations. SSTs are very sensitive to localised wind effects, which may not necessarily be represented in the relatively coarse resolution wind forcing used to drive the model. The latitudinal temperature gradient as well as the positions of the frontal bands are in good agreement with the observations. The extent of the Benguela upwelling system is well represented in both model simulations.

The southwestward penetration of the Agulhas Current, as represented by the $22^{\circ} \mathrm{C}$ isotherm, extends approximately $390 \mathrm{~km}$ further southwestward in the $\mathrm{O} 4$ experiment than the in the $\mathrm{O} 2$ experiment (Fig. 4). Suggesting a better representation of the Agulhas Current core, but the extent of the southwestward penetration still does not completely agree with the MW SSTs.

In terms of heat transport into the South Atlantic Ocean, the gap between the southern tip of Africa and the $17.9^{\circ} \mathrm{C}$ isotherm to the southwest is broader in $\mathrm{O} 4$, 

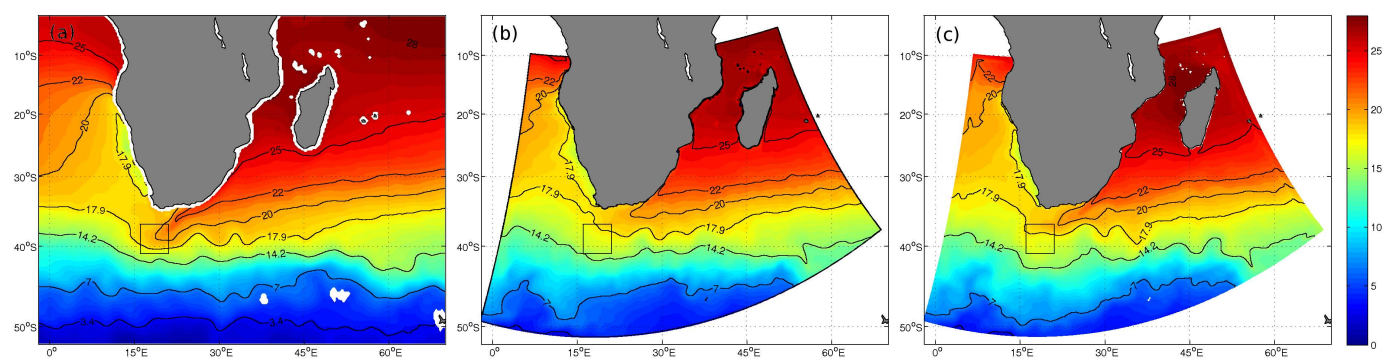

Fig. 4. Mean sea surface temperatures (SSTs, $\left.{ }^{\circ} \mathrm{C}\right)$ for the period 2004-2006 from MW SST (a), HYCOM O2 (b) and HYCOM O4 (c).

suggesting a significant improvement of the heat flux into the South Atlantic Ocean.

In order to quantify the differences between both model simulations and the SST observations in the retroflection region, weekly data has been averaged for the area $16-21^{\circ} \mathrm{E}$ and $37-41^{\circ} \mathrm{S}$ (indicated by the boxes in Fig. 4). The resulting time series were re-gridded to $1^{\circ} \times 1^{\circ}$ spatial resolution and averaged weekly in the case of the MW-SSTs. The mean and standard deviation are given in Table 2. The area was chosen such that an underestimate of the mean SST reflects a reduced southwestward penetration of the southern Agulhas Current.

There are some discrepancies between the Reynolds SST and the MW SST (Sect. 2.2). It has been shown that a horizontal resolution the $1^{\circ} \times 1^{\circ}$ resolution of the Reynolds SST is insufficient to capture the variability of narrow western boundary currents such as the Agulhas Current, and that observations of the Agulhas Current are significantly improved with the MW SSTs (Rouault and Lutjeharms, 2003). Nevertheless, in terms of model validation of SST for long time periods, the Reynolds SST provides a useful data set, especially since the optimally interpolated MW SST only became available in June 2002.

During the period from June 2002 to 2006, there is an average difference of $1.55^{\circ} \mathrm{C}$ between the $\mathrm{O} 2 \mathrm{SST}$ and the Reynolds SST (Table 2), which suggests that the O2 experiment underestimates the southwestward extent of the Agulhas Current significantly. There is a marked improvement in the O4 simulation, which compared to the Reynolds SSTs underestimates the temperatures by only $0.83^{\circ} \mathrm{C}$. Taking into account that the MW SSTs provide better observations of the Agulhas Current, the discrepancy is in fact $2.01^{\circ} \mathrm{C}$ for $\mathrm{O} 2$ and $1.29^{\circ} \mathrm{C}$ for $\mathrm{O} 4$.

The standard deviation for the $\mathrm{O} 2$ simulation is also significantly lower than the observations, $34 \%$ lower, and notably is also $17 \%$ less than $\mathrm{O} 4$, indicating that the 4 th order advection scheme improves the variability in the retroflection region.

The improved southwestward penetration of the temperature field in the $\mathrm{O} 4$ simulation suggests that the Agulhas Current core is stronger in this simulation experiment. To
Table 2. Statistics from the SST time series calculated for the period from June 2002 until December 2006, corresponding to the availability of the MW SST data with the launch of NASA's AQUA satellite.

\begin{tabular}{ccc}
\hline & Mean & Standard deviation \\
\hline HYCOM O2 & 16.83 & 1.05 \\
HYCOM O4 & 17.55 & 1.26 \\
Reynolds SST & 18.38 & 1.75 \\
MW SST & 18.84 & 1.59 \\
\hline
\end{tabular}

further investigate this, the vertical structure of the northern Agulhas Current, where good observations have been made, will be evaluated in the following Section.

\subsection{The vertical structure of the northern Agulhas Current}

The Agulhas Current near $32^{\circ} \mathrm{S}$ closely follows the narrow continental slope, and is known for its very stable, invariant, flow conditions. Gründlingh (1983) showed that the current, in this northern region, does not meander more than $15 \mathrm{~km}$ from its mean path. de Ruijter et al. (1999) in their study of the generation and evolution of Natal Pulses explain that the unusual stability of the current is due to the steepness of the continental slope. Natal Pulses are large cyclonic meanders in the northern Agulhas Current, which periodically interrupt its stable flow condition.

A year long current meter mooring array was deployed during the World Ocean Circulation Experiment (WOCE; Bryden et al., 1995) southeast of Durban near $32^{\circ} \mathrm{S}$ from February 1995 to April 1996. These measurements provide, to date, the best estimate of the time-averaged volume flux and the vertical structure of the Agulhas Current. Position and depths of the current meter mooring array are summarised in Table 3.

In general the core of the Agulhas Current can be found close to the coast, lying within $31 \mathrm{~km}$ of the coast $79 \%$ of the time. The current penetrates to depths of $2200 \mathrm{~m}$, and at its core, above $100 \mathrm{~m}$, velocities exceeding $100 \mathrm{~cm} \mathrm{~s}^{-1}$ are 

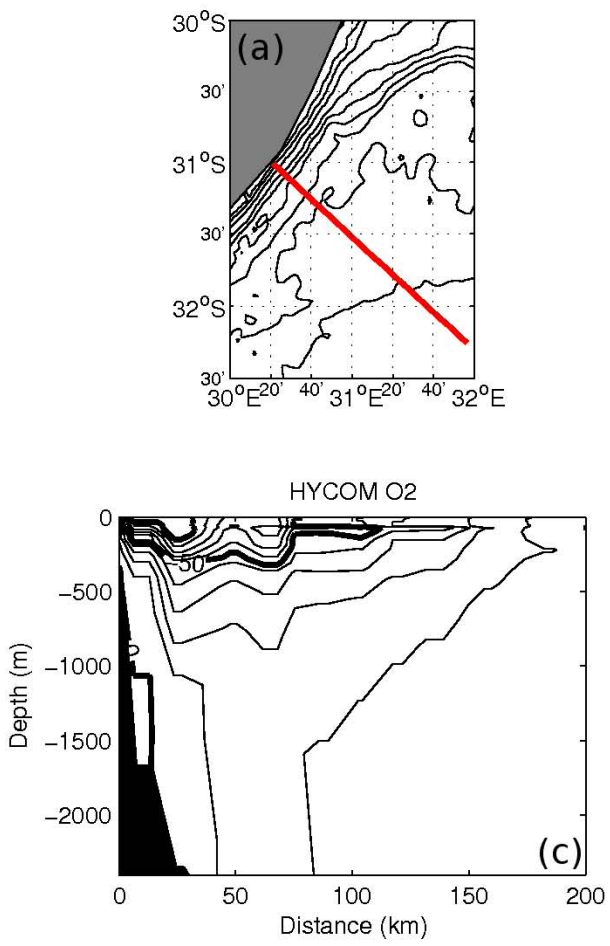
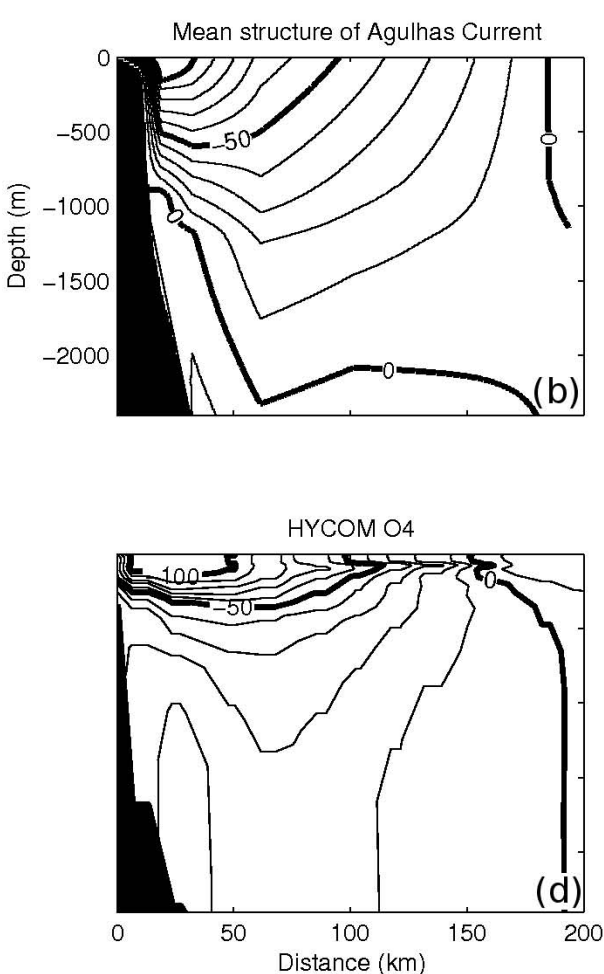

Fig. 5. Mean vertical structure of the northern Agulhas Current from Bryden et al. (2005)(b), HYCOM O2 (c) and HYCOM $\mathrm{O} 4$ (d). The velocities normal to the section are given in $\mathrm{cm} \mathrm{s}^{-1}$ and are plotted at $10 \mathrm{~cm} \mathrm{~s}^{-1}$ intervals. The section is indicated on the map (a) with the depth contours $100 \mathrm{~m}, 250 \mathrm{~m}$, and $500 \mathrm{~m}$ to $4000 \mathrm{~m}$ at $500 \mathrm{~m}$ intervals from etopo 2 bottom topography (http://www.ngdc.noaa.gov/mgg/fliers/01mgg04.html) indicated.

Table 3. Mooring positions and current meter depths deployed during the RRS Discovery Cruise 214 (Bryden et al., 1995).

\begin{tabular}{lcccccc}
\hline Mooring & A & B & C & D & E & F \\
\hline Latitude $\left({ }^{\circ} \mathrm{S}\right)$ & 3105.03 & 3105.30 & 3110.38 & 3120.55 & 3134.46 & 3154.51 \\
Longitude $\left({ }^{\circ} \mathrm{E}\right)$ & 3022.08 & 3025.44 & 3032.22 & 3046.60 & 3106.00 & 3128.24 \\
Current meter depths (m) & 138 & 384 & 403 & 353 & 353 & 388 \\
& 238 & 790 & 809 & 753 & 753 & 789 \\
& 439.5 & 1190 & 1209 & 1154 & 1154 & 1189 \\
& 740 & 1391 & 2010 & 1963 & 1963 & 1997 \\
Water depth (m) & 849 & 1480 & 2498 & 2900 & 2900 & 3446 \\
\hline
\end{tabular}

observed. The data also indicate that the offshore edge of the Agulhas Current, as determined by the position of the zero isotach, lies $203 \mathrm{~km}$ from the coast.

In order to compare the HYCOM simulations to the above described data, a section was defined corresponding to the positions of the year long mooring array, extending from the coast at Port Edward to $220 \mathrm{~km}$ offshore, and velocities normal to this section were extracted from the model (Fig. 5). The weekly velocities were averaged over a 9 month period and compared to the mean structure described in Bryden et al. (2005), here shown as Fig. 5 b.
From the zero isotach in HYCOM O2, the outer edge of the current lies $200 \mathrm{~km}$ from the coast, while in HYCOM O4 the current lies closer, between $150-200 \mathrm{~km}$ from the coast.

The characteristic V-shaped structure of western boundary currents is much better represented in the $\mathrm{O} 4$ simulation, with the maximum current velocity moving away from the coast with depth. In both HYCOM simulations, the current extends all the way to the bottom, with $10 \mathrm{~cm} \mathrm{~s}^{-1}$ velocities evident at depths of $3000 \mathrm{~m}$. This is deeper than indicated by the observations by Bryden et al. (2005), where according to the zero isotach the current extends to $2200 \mathrm{~m}$, and 
this is most likely due to a lack of vertical resolution in the model. The model representation of the vertical structure is limited to 30 vertical hybrid layers. In particular for the deeper regions, where density changes are small, more vertical layers may have provided a better solution. Nevertheless, the $20 \mathrm{~cm} \mathrm{~s}^{-1}$ isotach lies at $1200-1300 \mathrm{~m}$ approximately 60 $70 \mathrm{~km}$ offshore in HYCOM O4, in very good agreement with the observations. The $20 \mathrm{~cm} \mathrm{~s}^{-1}$ isotach in the $\mathrm{O} 2$ experiment only extends to about $800-900 \mathrm{~m}$ depths. The $50 \mathrm{~cm} \mathrm{~s}^{-1}$ isotach can be found at about $400 \mathrm{~m}$ depth in both simulations, while it is $300 \mathrm{~m}$ deeper in reality.

Velocities exceeding $100 \mathrm{~cm} \mathrm{~s}^{-1}$ above $100 \mathrm{~m}$ are evident in both simulations, but are more strongly defined in the $4^{\text {th }}$ order advection scheme. The outer edge of the $100 \mathrm{~cm} \mathrm{~s}^{-1}$ velocities extend offshore to $50 \mathrm{~km}$ compared to $30 \mathrm{~km}$ in the $\mathrm{O} 2$ simulation. In general this indicates that the current velocities are weaker in the $\mathrm{O} 2$ simulation, which has implications in terms of the southwestward penetration of the Agulhas Current, which was shown to be reduced in the SST comparison (Sect. 3.2).

Overall, it is clear that the $\mathrm{O} 4$ simulations provides a much better representation of the vertical structure of the Agulhas Current in good agreement with the observations. The transports derived from this section will be discussed in relation to the observations in the following Sect. (3.4).

\subsection{Transport in the northern Agulhas Current}

Bryden et al. (2005) calculated the time-averaged volume transport, by integrating the velocities from the coast to $203 \mathrm{~km}$ offshore and to a depth of $2400 \mathrm{~m}$. The daily transports were averaged over 267 days from 5 March to 27 November 1995 to yield a mean poleward transport of $69.7 \pm 21.5 \mathrm{~Sv}\left(1 \mathrm{~Sv}=1 \times 10^{6} \mathrm{~m}^{3} \mathrm{~s}^{-1}\right)$.

For the comparison to HYCOM, the weekly transports were calculated across the same section (Fig. 5a) and integrated to a depth of $2400 \mathrm{~m}$. The mean transports and their standard deviations were calculated for HYCOM for the entire period from the beginning of 2001 to the end of 2006, as well as for 9 months of each year, corresponding to the 267 days over which the mooring data transports were calculated (Table 4).

On average, the $\mathrm{O} 2$ simulation underestimates the observed poleward volume transport by $21.4 \mathrm{~Sv}$. This is improved in the $\mathrm{O} 4$ experiment, where the transports are only 12.2 Sv less than estimated by Bryden et al. (2005), within one standard deviation of the observed mean.

The yearly running mean transports (Fig. 6) of HYCOM $\mathrm{O} 4$ oscillate around $\sim 60 \mathrm{~Sv}$, while in HYCOM O2 they decrease by approximately $\sim 20 \mathrm{~Sv}$ between 2001 and 2006, indicating that the second order advection scheme is subject to a degree of model drift throughout the simulation.

In the discussions of the vertical structure of the Agulhas Current (Sect. 3.3) it was shown that the vertical characteristics of the Agulhas Current are much improved in the $\mathrm{O} 4$
Table 4. Northern Agulhas Current transport statistics. Note the inverted convention from Bryden et al. (2005), the maximum transport was considered to be positive and poleward.

\begin{tabular}{cccc}
\hline & Period & Mean & Std \\
\hline Bryden et al. (2005) & 05/03-27/11/1995 & 69.7 & 21.5 \\
HYCOM O2 & $2001-2006$ & 48.3 & 19.6 \\
& 2001 & 52.9 & 19.7 \\
& 2002 & 52.4 & 17.7 \\
& 2003 & 52.3 & 21.7 \\
& 2004 & 48.3 & 16.8 \\
HYCOM O4 & 2005 & 42.4 & 13.3 \\
& 2006 & 37.7 & 17.8 \\
& $2001-2006$ & 57.5 & 19.9 \\
& 2001 & 56.9 & 22.2 \\
& 2002 & 54.1 & 17.7 \\
& 2003 & 60.7 & 18.1 \\
& 2004 & 64.4 & 27.5 \\
& 2005 & 55.6 & 19.6 \\
& 2006 & 51.8 & 17.56 \\
\hline
\end{tabular}

scheme. A much deeper and well-defined current is evident, which (partially) accounts for an increase in the transports. Additionally, there is a $1^{\circ} \mathrm{C}$ increase in the vertical temperatures of the upper $100 \mathrm{~m}$ and a 0.2 psu increase in salinity in the upper $200 \mathrm{~m}$ in the $\mathrm{O} 4$ scheme (not shown). This results in enhanced temperature and salinity gradients of the upper $500 \mathrm{~m}$, and according to the thermal wind equation an increased density gradient will result in an increased transport. Furthermore, as will be shown in Sect. 4, there is an overall increase of mesoscale variability in the $\mathrm{O} 4$ scheme. The Agulhas Current transport is sensitive to mesoscale eddies, and their enhancement also acts to increase the average transport.

In HYCOM there is no indication of a seasonal signal of the transports, although some interannual signals seem to be evident.

The volume flux in the Agulhas Current is always poleward, varying between $8.9 \mathrm{~Sv}$ and $121.0 \mathrm{~Sv}$ (Bryden et al., 2005). Apart from the last week in April 2006 in HYCOM $\mathrm{O} 2$ where the transport is negative (equatorward currents in this instance were caused by the passage of a mesoscale eddy), both experiments simulate predominately poleward transports (Fig. 6), ranging from 9.4 Sv to $108.4 \mathrm{~Sv}$ (HYCOM O2) and from 6.9 Sv to $124.2 \mathrm{~Sv}$ (HYCOM O4). The weekly transports are generally stronger (poleward) in HYCOM O4 than in HYCOM O2, in particular the extremes (not shown).

The minimum and maximum velocities in both simulation experiments are always associated with the southwestward passage of anticyclonic eddies. These transport fluctuations occur between 4-6 time per year, in good agreement with the occurrence of southwestward propagating Mozambique Channel eddies. They were previously shown to appear in the 
Mozambique Channel 5-6 times per year, frequently interacting with the northern Agulhas Current (Backeberg et al., 2008). The advection of these eddies are clearly responsible for the large fluctuations in Agulhas Current transport.

From these comparisons, it is evident that the $\mathrm{O} 4$ simulation provides stronger poleward transports within the Agulhas Current core. Additionally, it seems that these are significantly contributed toward by upstream mesoscale variability. An increase in mesoscale variability in the $\mathrm{O} 4$ scheme seems to be the cause of the enhanced transports, considering that the 4th order scheme has been documented to increase the eddy kinetic energy in model simulations (Winther et al., 2007). According to previous studies (e.g. Backeberg et al., 2008) these also have an impact on the dynamics at the retroflection, influencing the heat transport and therefore the Indo-Atlantic inter-ocean exchange. Assuming that these fluxes are predominantly influenced by the mesoscale variability, it is therefore important to examine and quantify the eventual relationship between the upstream and downstream dynamics.

\section{Analyses of the mesoscale variability}

In this Section mesoscale variability associated with sea surface heights are analysed using the satellite altimetry data as well as the two model simulations. Due to the fact that the mesoscale signals in the greater Agulhas Current region are quite strong the inter-comparison with altimetry measurements yields a good opportunity to validate model simulations.

\subsection{Sea surface height variations}

To convert altimeter measurements into dynamically meaningful quantities, the exact position of the sensor with respect to the geoid is required. To date the precision of the geoid is insufficient to allow for useful dynamical calculations of wavelengths shorter than about $2000 \mathrm{~km}$ (Le Traon, 2002). In terms of comparing the mean flow, the mean dynamic topography of the model simulation differs from the observations, there is an offset of about $150 \mathrm{~cm}$ between the AGULHAS HYCOM and Rio05 (Rio et al., 2005) mean dynamic topography but the gradients are similar (not shown), therefore they are comparable. From the geostrophic assumption, the mean SSH contour lines (Fig. 7, black) depict the mean surface circulation pathway.

Altimeter based sea level anomalies and estimation of eddy kinetic energies (or its proxy: standard deviation of $\mathrm{SSH}$ ) are routinely used to assess the performance of eddyresolving/-permitting ocean models (Treguier et al., 2003). The standard deviation ( $\nabla$, Eq. 1, Fig. 7, colour scheme) is

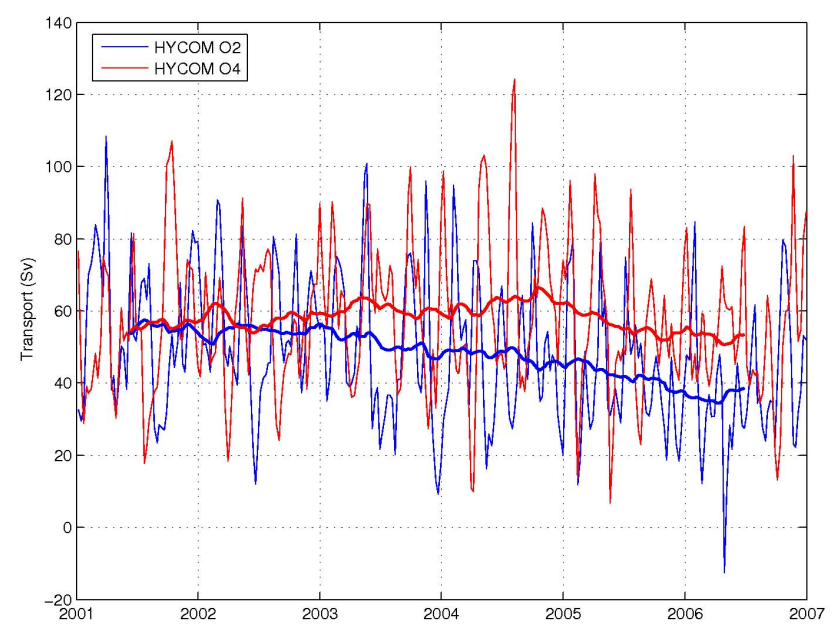

Fig. 6. Agulhas Current weekly transports at $32^{\circ} \mathrm{S}$ integrated to $2400 \mathrm{~m}$ from HYCOM O2 (blue) and O4 (red), with the corresponding yearly running means. The running means for the first and last 6 months have been excluded due to edge effects of the running mean window.

the variability about the time mean, and hence differences in the mean dynamic topography do not come into play.

$\nabla=\sqrt{\frac{1}{n}\left[\sum \eta^{2}-\frac{1}{n^{2}}\left(\sum \eta\right)^{2}\right]}$

where $n$ is the number of observation and simulation weeks, and $\eta$ is the sea surface height.

North of Madagascar, near the open boundary, the jet associated with the South Equatorial Current (SEC) seems to be slightly stronger in the $\mathrm{O} 4$ versus the $\mathrm{O} 2$ simulation, while the jet in the altimetry observations appears to be stronger than the model experiments. This is most likely due to inherent weaknesses from the parent model.

In the Mozambique Channel, there is no clearly defined current indicated by the streamlines from the altimetry SSH. The high levels of variability indicate, in agreement with the previous literature, that the flow here is dominated by the passage of eddies. Both model runs are able to simulate these high levels of mesoscale variability. Slightly stronger variability is evident in the $\mathrm{O} 4$ experiment, suggesting that the eddies are more frequent and/or more energetic in the 4th order advection scheme.

Both model simulations depict the mean path of the southern extension of the East Madagascar Current (SEMC). The mean SSH streamlines retroflect in an anticyclonic direction to flow eastward into the South Indian Ocean. Higher levels of mesoscale variability are encountered due to this retroflecting current, with occurrences of both cyclonic and anticyclonic eddies as reported by Siedler et al. (2009). The 


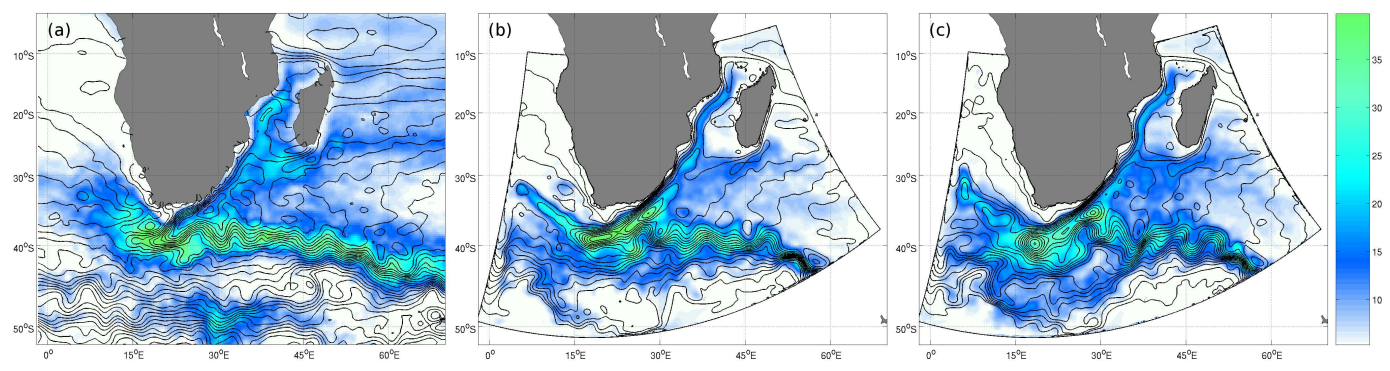

Fig. 7. Sea surface height (SSH) mean (black contours, spaced every $7.5 \mathrm{~cm}$ ) and standard deviation $(\nabla$, colour scheme in $\mathrm{cm})$ from Aviso MADT (a), HYCOM O2 (b) and HYCOM O4 (c) for the period from 2001 to 2006, inclusive.

variability in the $\mathrm{O} 4$ simulation is slightly broader and more energetic but remains lower than observed from altimetry.

In the northern Agulhas Current, the simulation experiments overestimate the current strength in comparison to the altimetry. In particular north of $34^{\circ} \mathrm{S}$, the narrow separation between SSH streamlines indicate a strong gradient and hence an intensification of the mean geostrophic current. However, as mentioned previously, the quality of the data from Aviso close to the coast is questionable and the Agulhas Current is known to remain within $31 \mathrm{~km}$ of the coast $79 \%$ of the time in this region (Bryden et al., 2005).

The mesoscale variability in this northern part of the Agulhas Current, is predominantly confined to the offshore side of the current. This is evident from the enhanced variability offshore of the northern Agulhas Current, in both model simulations as well as the altimetry.

In the southern Agulhas Current, the current is again sufficiently far away from the coast for the altimetry data to recapture its flow. Comparing the trajectories of the southern Agulhas Current mean flow, between $20^{\circ}-28^{\circ} \mathrm{E}$ and $34^{\circ}-$ $38^{\circ} \mathrm{S}$, the core of the current is too far south in HYCOM O2, suggesting that it separates from the continental shelf prematurely. In the 4th order simulation, the southwestward extent of the Agulhas Current core is much narrower and extends further southwestward than in the 2 nd order experiment. Its trajectory is also slightly further north.

As the southern Agulhas Current separates from the coast, following the continental shelf break, it continues southwestward as an unstable, meandering current. In turn the SSH standard deviation reveals a narrow band of high variability, along the continental shelf break north of $36^{\circ} \mathrm{S}$ between $22^{\circ}$ and $26^{\circ} \mathrm{E}$. In the $\mathrm{O} 2$ simulation this narrow band is completely masked by excessively high and broad standard deviation values assumed to be caused by the distinct train of eddies extending from the Agulhas Plateau to the retroflection (Backeberg et al., 2008). In the $\mathrm{O} 4$ scheme a narrow band of high variability is encountered, suggesting that it is able to simulate the southern Agulhas Current as a meandering current, rather than a train of eddies. This will be confirmed later using sea level skewness (Sect. 4.2.2).
The distribution and pattern of the standard deviation in the retroflection area is improved in HYCOM O4. The maximum variability associated with the retroflection in HYCOM $\mathrm{O} 2$ is confined in its latitudinal distribution, lying between $37^{\circ}$ and $40^{\circ} \mathrm{S}$. Whereas in HYCOM O4 it extends further south in better agreement with the altimetry observations. Furthermore high values of standard deviation are focussed about the mean postion of the retroflection $\left(17^{\circ} \mathrm{E}\right.$ and $\left.39^{\circ} \mathrm{S}\right)$, in good agreement with variability seen in the altimetry.

The Agulhas Ring shedding corridor in HYCOM O2 is confined to a very narrow band extending northwestward from the retroflection. This indicates that eddies and rings shed from the retroflection prefer to travel along this one trajectory. The strength and pattern of the standard deviation distribution is less focused in the northwest direction in the $\mathrm{O} 4$ experiment. In comparison this agrees better with the spatial distribution of variability observed from altimetry suggesting that, although the higher-order momentum advection scheme seems to underestimate the variability for the region compared to observations, it is able to simulate more variable eddy trajectories in the ring shedding corridor.

The meandering pathway of the Agulhas Return Current, is represented by the narrowly spaced band of mean SSH contours and high standard deviation at about $40^{\circ} \mathrm{S}$ between $20^{\circ}$ and $60^{\circ} \mathrm{E}$ in the altimetry. It is known to have three main quasi-stationary meanders (e.g. Boebel et al., 2003) and these are well represented in the simulated mean SSH field. Although slightly lower levels of variability are observed. The second and third meanders, with their northern troughs near $33^{\circ}$ and $39^{\circ} \mathrm{E}$, are more clearly defined in the $\mathrm{O} 4$ experiment.

In summary there are marked improvements from applying the 4th order advection scheme in HYCOM for the Agulhas Current simulations. In particular the strength and distribution of the mean flow (mean SSH) and variability $(\nabla)$ in the southern Agulhas Current associated with the transition from a more stable current upstream to a strongly meandering and retroflecting current downstream appears to be more reliable in HYCOM O4 when compared to altimetry. 


\subsection{Sea level skewness}

The above comparisons are qualitative, and more quantitative analyses need to be performed in order to objectively assess these simulation results.

Sea level skewness has been proposed by Thompson and Demirov (2006) as a new method for using SSH measurements from altimetry in model validation and mesoscale variability studies.

Skewness is a measure of the asymmetry of the distribution of a variable, or just the normalised third moment about the mean. It is given by $\gamma_{1}$ (Eq. 2), of which we will consider the classical unbiased estimate (Eq. 3).

$\gamma_{1}=\frac{\frac{1}{n} \sum_{i=1}^{n}\left(x_{i}-\bar{x}\right)^{3}}{\left[\frac{1}{n} \sum_{i=1}^{n}\left(x_{i}-\bar{x}\right)^{2}\right]^{\frac{3}{2}}}$

$\gamma_{\eta}=\frac{\sqrt{n(n=1)}}{n-2} \gamma_{1}$

$\gamma_{\eta}$ denotes the unbiased skewness of SSH $(\eta)$ for a sample of $n$ values, $x_{i}$ is the $i^{t h}$ value and $\bar{x}$ the sample mean.

Thompson and Demirov (2006) show that in an idealised example of a meandering current, standard deviation of $\mathrm{SSH}$ is a function of position, with the maximum variability occurring at the mean position of the current, where the sea surface gradient is greatest.

Similarly, skewness is also a strong function of the cross current position. It is zero at its mean position, where changes in the sea surface height induced by the meandering current are symmetric. Therefore in a meandering current it is possible to infer its mean position from the zero line of the skewness. Moreover, as the skewness increases toward lower mean sea levels, a geostrophic flow to the left (right) can be inferred in the Southern (Northern) Hemisphere.

In regions with an abundance of eddies, the skewness field allows for the preferred sense of rotation to be determined. Consider the following two situations: (1) one large anticyclonic eddy and one large cyclonic eddy of the same dimension, and (2) one large anticyclonic eddy and two small cyclonic eddies. For the two situations, the mean SSH and its standard deviation may be the same but the skewness will be zero in situation (1) and negative in situation (2). Therefore negative (positive) skewness indicates a preference for cyclonic (anticyclonic) rotation.

Thompson and Demirov (2006) conclude that the skewness analysis is a useful statistical method for validating high resolution ocean models. In the following Section sea level skewness determined from altimetry is assessed for greater Agulhas Current region and then used to assess the model simulations. To our knowledge, this is the first time that sea level skewness is used in model validation.

\subsubsection{Assessment from altimetry measurements}

In order to evaluate the sea level skewness field it is compared to the mean geostrophic currents derived from altimeter SSH measurements (Fig. 8a) and to the fraction contribution of anticyclonic eddies toward the total EKE (Fig. 8b). The method of distinguishing between cyclonic and anticyclonic rotation by calculating the fraction from total EKE was used in the study of the southern extension of the East Madagascar Current (Siedler et al., 2009), but here was applied to the entire greater Agulhas Current domain.

The zero skewness line seems to indicate the mean positions of meandering currents northwest of Madagascar, in the southern Agulhas Current, and in the Agulhas Return Current (Fig. 8a). The fraction of anticyclonic EKE from the total seems to explain most of the pattern evident in the sea level skewness field (Fig. 8b).

The flow in the Mozambique Channel is dominated by southward moving anticyclonic eddies (e.g. Sætre and da Silva, 1984; Biastoch and Krauss, 1999; de Ruijter et al., 2002), and most of the variability associated with these eddies is located toward the centre of the channel (Fig. 7a), contributed to mostly by anticyclonic eddies (Fig. 8b). The skewness field (Fig. 8a) is predominantly positive here in good agreement with the fraction of anticyclonic EKE. Near the Mozambican coast there is a preference for cyclonic rotation, consistent with cyclonic shear edge eddies forming from friction at the continental shelf edge. However, the skewness field does not indicate the presence of cyclonic shear. This may be related to the fact that skewness cannot distinguish between an eddy field with an equal mix of cyclonic and anticyclonic eddies of the same intensity and a region with no eddies.

The two modes of the southern extension of East Madagascar Current (SEMC) described by Siedler et al. (2009) are clearly evident in the skewness field. The current consistently retroflects southwest of Madagascar near $42^{\circ} \mathrm{E}$, with anticyclonic motion (and eddies) favoured during a southwestward extension of the SEMC, while cyclonic motion (and eddies) occurs during westward flow along the south Madagascar continental shelf edge. For the SEMC the zero skewness line (Fig. 8a) does not seem to indicate the mean position of the westward outflow. The mean geostrophic currents are located within the area of negative skewness, indicating that the SEMC outflow is not a meandering current.

The tongue of positive sea level skewness, extending from south of Madagascar toward the Agulhas Current, was suggested to represent anticyclonic eddies propagating westward (Thompson and Demirov, 2006). Moreover, these are thought to be one of the mechanisms by which Natal Pulses are triggered in the northern Agulhas Current (Schouten et al., 2002). The occurrence of anticyclonic eddies in this region has been confirmed by (e.g. Siedler et al., 2009), and is also clearly evident in the fraction of anticyclonic EKE (Fig. 8b). 

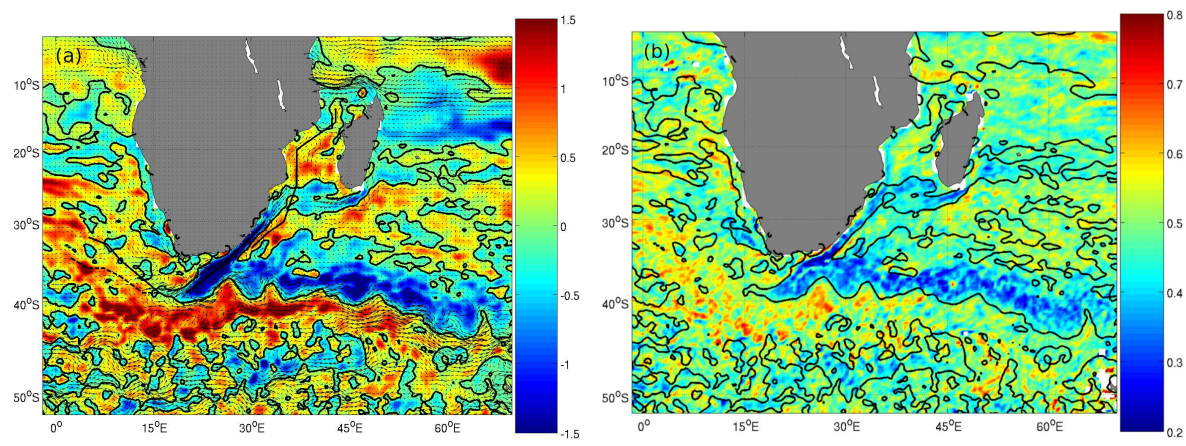

Fig. 8. (a) Sea level skewness (colour scheme indicates positive and negative) with mean geostrophic currents derived from altimetry SSH measurements (vectors). (b) The fraction of anticyclonic EKE from the total EKE. The data period spans from 2001 to 2006 , inclusive. The solid black contour indicates zero skewness.

Natal Pulses are large cyclonic meanders, that form at the Natal Bight, on the east coast of South Africa near $29^{\circ} \mathrm{S}$. Their average offshore extent is $170 \mathrm{~km}$ and they form approximately 6 times per year (Lutjeharms and Roberts, 1988). These periodically interrupt the stable flow conditions of the northern Agulhas Current as they propagate southwestward along the South African east coast.

The band of negative skewness extending about $150 \mathrm{~km}$ offshore along the east coast of South Africa from $26-35^{\circ} \mathrm{S}$ indicates that there is a preference for cyclonic disturbances in the mean current, consistent with what is known of Natal Pulses. The fraction of anticyclonic EKE (Fig. 8b) is low, and confirms that up to $80 \%$ of the variance is from cyclonic meanders. However the total EKE (cyclonic + anticyclonic; Fig. 7a) is very low, suggesting a rather stable current with relatively infrequent occurrences of Natal Pulses. In fact, most of the EKE, between $26^{\circ}$ and $35^{\circ} \mathrm{S}$ is located on the offshore side of the Agulhas Current, and is mainly due to anticyclonic eddies. These EKE maxima might be connected with anticyclonic eddies frequently originating at the SEMC and the Mozambique Channel.

Upon approaching the Agulhas retroflection, between $21^{\circ}-27^{\circ} \mathrm{E}$ and $35^{\circ}-40^{\circ} \mathrm{S}$, the skewness field as well as the fraction of anticyclonic eddies in total EKE, indicate predominantly cyclonic rotation in the southern Agulhas Current. This might be related to the arrival of Natal Pulses in combination with westward propagating cyclonic eddies pinched off from the northern extremities of the meandering Agulhas Return Current.

The zero skewness line in the southern Agulhas Current closely follows the mean position of the current. In particular southwestward of $22^{\circ} \mathrm{E} / 37^{\circ} \mathrm{S}$, at the southern termination of the Agulhas Bank, where the current separates from the continental shelf break and continues southwestward as a meandering current. As such the skewness field is able to determine the mean position of a meandering current, and approaching the Agulhas retroflection region, is in good agree- ment with the fraction of anticyclonic EKE.

In the ring shedding corridor the tongue of positive skewness extending into the South Atlantic Ocean, indicates a preference for anticyclonic eddies. Thompson and Demirov (2006) discuss that it has been shown that cyclonic eddies which occur closer to the South African west coast travel west-southwest from this position, while anticyclonic Agulhas Rings travel west-northwest from the Agulhas retroflection (e.g. Richardson and Garzoli, 2003; Matano and Beier, 2003; Treguier et al., 2003). They argue that if the relative contributions of cyclonic and anticyclonic eddies are equal, the skewness will be zero (as in situation 1, Sect. 4.2). It may be possible that these cancel each other out closer to the coast and hence cause the southward displacement of the ring shedding corridor.

In the meandering Agulhas Return Current the zero skewness line provides a really good indication of the mean position of the current, and its quasi-stationary meanders.

\subsubsection{Comparison to HYCOM simulations}

The skewness field has been calculated from HYCOM O2 and $\mathrm{O} 4$ SSH fields (Fig. 9) as a means to validate and compare the two simulations as well as provide new insight into mesoscale dynamics simulated in the model.

The current to the northwest of Madagascar is well represented in both simulations, the zero skewness line indicating the mean path at $10^{\circ} \mathrm{S}$, in agreement with the altimetry skewness field (Fig. 8).

Moreover, a preference for anticyclonic eddies in the Mozambique Channel is well represented in both HYCOM simulations, in good agreement with the observations.

In the SEMC, contrary to the altimetry sea level skewness, there is a preference for anticyclonic rotation in the model simulations. However, a band of negative skewness extending toward Mozambique west of Madagascar's southern tip in the $\mathrm{O} 4$ scheme suggests that it is able to reproduce the bimodal pattern discussed in Siedler et al. (2009). Although 


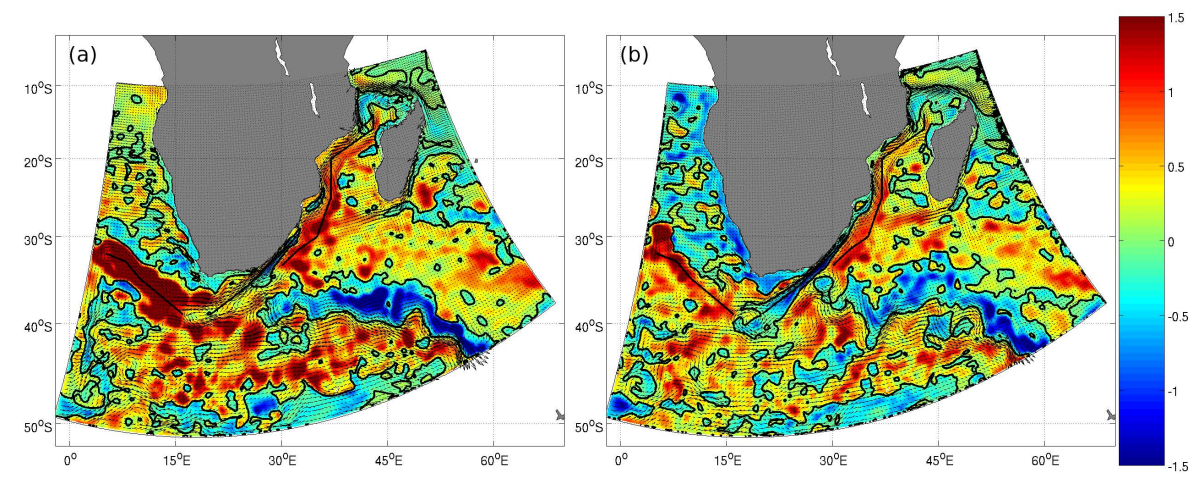

Fig. 9. Sea level skewness (colour scheme) with the black contour indicating zero skewness and mean surface currents (vectors) from HYCOM O2 (a) and O4 (b). The data period spans from 2001 to 2006, inclusive.

this pattern is not as pronounced as in the altimetry skewness field, it is completely absent in HYCOM O2.

The most striking improvement from applying the 4th order advection scheme can be seen in the Agulhas Current proper. The band of negative skewness along the east coast of South Africa extends all the way to the retroflection region, near $40^{\circ} \mathrm{S}$, in good agreement with the observations from altimetry. This indicates that the $\mathrm{O} 4$ scheme is able to simulate the Agulhas Current as a well defined current core, with the periodic occurrence of cyclonic disturbances or Natal Pulses. This band of negative skewness is much shorter in $\mathrm{O} 2$ extending from $32^{\circ} \mathrm{E} / 29^{\circ} \mathrm{S}$ to $25^{\circ} \mathrm{E} / 35^{\circ} \mathrm{S}$, the northern tip of the Agulhas Plateau.

In the southern Agulhas Current the zero skewness line from the $\mathrm{O} 4$ scheme lies within the centre of the mean position of the current. According to Thompson and Demirov (2006), the zero skewness line will only indicate the mean position of a current, when it freely meanders. The $\mathrm{O} 4 \mathrm{sim}$ ulation results therefore suggest that the southern Agulhas Current is represented as a meandering current, as opposed to a train of eddies evident in the $\mathrm{O} 2$ scheme (Backeberg et al., 2008).

The skewness distribution of the $\mathrm{O} 4$ scheme at the $\mathrm{Ag}$ ulhas retroflection is generally in better agreement with the altimetry skewness field. Along the continental shelf of the Agulhas Bank, for instance, there is a narrow band of positive skewness north of the negative skewness band, which continues westward at the southern termination of the Agulhas Bank. The ring shedding corridor is less focussed in $\mathrm{O} 4$, indicating a more realistic representation of the variability associated with the Agulhas retroflection ring shedding.

In both simulations the meandering Agulhas Return Current is only represented by the zero skewness line east of $30^{\circ} \mathrm{E}$, which seems to indicate that not enough flow is returning eastward from the retroflection. In particular, the second meander, with its southern trough near $35^{\circ} \mathrm{E}$ extends too far south in the $\mathrm{O} 4$ simulation, while it seems to be more realis- tically portrayed in the 2 nd order advection scheme. Moreover, the negative (positive) skewness north (south) of the mean position of the return current is well pronounced in both simulation experiments, although not as strong or persistent as found in the altimetry analyses.

In summary, the 4th order advection scheme significantly improves the dynamic characterisation of the southern Agulhas Current, revealing a well-defined meandering current, with distinct bands of cyclonic and anticyclonic eddies.

\subsection{Variogram analysis}

In this Section the spatial scales of mesoscale features are discussed. The (semi-)variogram, is a geostatistical technique which characterises the spatial correlation within a data set and quantifies variability as a function of scale (Wackernagel, 1998).

In geostatistics, analyses of spatial data often rely on the assumption of stationarity for the random process (Gneiting et al., 2001). In the stationary case, the variogram can be simply deduced from the covariance as $C 0-C(h)$, where $C 0$ is the variance and $C(h)$ the covariance. The variogram averages squared differences of the variable, which filters the influence of a spatially varying mean. Therefore, the variogram can be defined in some cases where the covariance function cannot. For example in the non-stationary case, the variance may keep increasing with increasing lag, rather than leveling off, corresponding to an infinite global variance. In this case the covariance function is undefined, while the variogram remains valid.

Dissimilarities $(\gamma)$ between sample pairs are calculated by computing the squared difference between the values (Eq. 4), and these are plotted against the separation of the sample pairs in geographical space, or lag $(h)$, to form the variogram cloud. The lag distances are grouped into classes $\left(H_{k}\right)$, and within each class the dissimilarities are averaged to form the sequence of values of the experimental variogram. The dissimilarities depend on the spacing and on the orientation of 
the point pair described by the lag vector, and because it is a squared quantity, the order in which the points in space are considered does not come into play. Therefore the variogram is symmetric with respect to $h$.

$\gamma\left(H_{k}\right)=\frac{1}{2 n_{c}} \sum_{\alpha=1}^{n_{c}}\left(\eta\left(x_{\alpha}+h\right)-\eta\left(x_{\alpha}\right)\right)^{2}$ with $h \in H_{k}$

$n_{c}$ are all the point pairs that can be linked by a vector, $h$. The average dissimilarity with respect to a vector class within a specific interval $H_{k}$, is a value of the experimental variogram $\gamma\left(H_{k}\right)$.

Usually the average dissimilarity between values increases with distance between point pairs, as near samples tend to be more alike. If the variable is stationary, at large distances between point pairs the experimental variogram may reach a sill, its maximum. When this occurs the expression converges to twice the variance, therefore dividing by 2 means that the sill approximates the variance within the data. At scales exceeding the natural scale of the phenomena in question, harmonic effects may be noted, in which the variogram peaks and dips at lag distances that are multiples of the natural scale, this is known as cyclicity.

An abrupt change of the slope of the dissimilarity function at a specific scale indicates that an intermediate level of variation has been reached, this is known as the range. It identifies the distance from the origin where the variogram reaches its maximum value (the sill), at which point the sampled variable exhibits its maximum variance.

The behaviour of the variogram near the origin is important to note, it characterises the very small scales within a dataset and indicates the type of continuity of the variable: differentiable, continuous but not differentiable, or discontinuous. A discontinuous variogram at the origin is known as a nugget effect, which indicates that the values of the variables change abruptly at very small scales, it may also arise when data is sparse or from measurement error.

A theoretical curve is fitted to the variogram in order to attribute a physical meaning to them. The fit is done by eye, because emphasis is not placed on how well the variogram function fits the the sequence points, but rather what type of continuity is assumed near the origin. The fit therefore implies an interpretation of the behaviour of the variogram at the origin and its behaviour at large lag distances.

\subsubsection{Comparison to a spatial fourier analysis}

A spatial Fourier and variogram analysis of modelled SLA data (HYCOM O2) are compared in order to confirm for an oceanographic application, that the variogram indicates the scale up to which a spatial correlation exists between data points, thus giving an indication of the size of mesoscale features. The comparison is done for modelled SLA data along a section in the Mozambique Channel where large anticyclonic eddies, up to $300 \mathrm{~km}$ in diameter, are known to occur frequently (HYCOM O2; Backeberg et al., 2008).
Figure 10a is the time averaged spatial FFT spectrum for the modelled SLA data along the section indicated in Fig. 9a. Notice the peak near $L_{w} \cong 560 \mathrm{~km}$, which for a Fourier analysis typically corresponds to two eddies (cyclonic and anticyclonic) with diameters of about $280 \mathrm{~km}$, in agreement with the simulated eddies observed in HYCOM O2 for the Mozambique Channel (Backeberg et al., 2008).

The blue curve (Fig. 10b) indicates the corresponding experimental variogram calculated using Eq. (4), and the red curve is the theoretical variogram fitted to the sequence (Eq. 5), which in this case is a combination of a Gaussian and a cosine function. Other functions were tested (cardinal sine, cubic, exponential) with less success.

$\gamma(h)=C_{g}\left[1-\exp \left(-\frac{h^{2}}{a_{g}^{2}}\right)\right]+C_{c}\left[1-\cos \frac{2 \pi h}{a_{c}}\right]$

$C$ is the amplitude of the Gaussian/cosine function, $h$ the distance between points and $a$ the range, or radius. In Eq. (5) the subscripts $g$ and $c$ refer to the Gaussian and cosine variables, respectively. Note that in a Gaussian model the range $a_{g}$ corresponds to a length scale of $a_{g} \times 2.5$, which in this case is $275 \mathrm{~km}\left(a_{g}=110 \mathrm{~km}\right)$.

Mozambique Channel eddies in HYCOM O2 are all of very similar sizes. Therefore, the typical mesoscale size indicated by the Fourier analysis should be of a similar size to the maximum mesoscale estimated by the variogram. In this case, the mesoscale estimate from the variogram is $275 \mathrm{~km}$ and the estimate from the Fourier analysis is $280 \mathrm{~km}$, in good agreement with each other as expected.

In addition to this, the combined Gaussian and cosine fit indicates a mixture of periodic (cosine) and other (Gaussian) signals. Here the periodic signal suggests a succession of eddies. The cosine range $\left(a_{c}=90 \mathrm{~km}\right)$ indicates that successive eddies are typically $\sim 560 \mathrm{~km}\left(a_{c} \times 2 \pi\right)$ apart.

Both the spatial Fourier and variogram analyses reflect the whole range of spatial scales related to mesoscale currents for a given region. Therefore it may be prudent to refer to "mesoscale features" rather than "eddies" when discussing these results. However, due to the dominance of anticyclonic eddies (in HYCOM O2) in the Mozambique Channel it may be safe to conclude that these results provide an indication of the typical (Fourier) and maximum (variogram) eddy diameters. For consistency, discussions hereafter will refer to "mesoscale features" only, and these are defined to include both eddies and meanders in mesoscale currents.

The information contained in a variogram is in principle equivalent to that contained in a Fourier transform, but the variogram is more practical for testing the stationarity of a variable and for examining small scales. In addition to this the Fourier transform relies on the assumption that the data domain is periodic rather than infinite. Furthermore, when calculating the experimental variogram the data does not need to be preprocessed. Before calculating the Fourier 

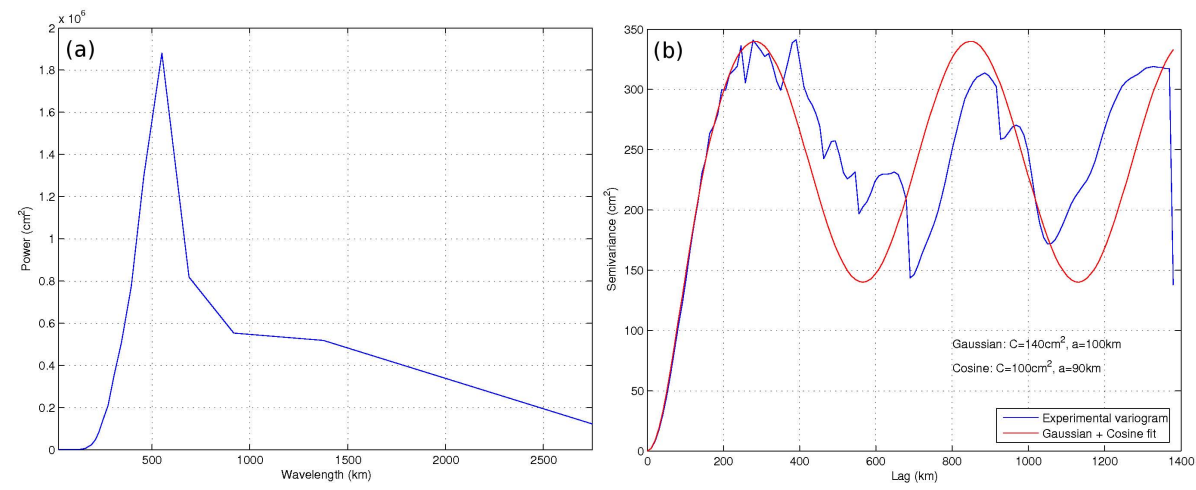

Fig. 10. Spatial FFT spectrum (a) and variogram analysis (b) of model SLA data from HYCOM O2 along a section in the Mozambique Channel. The section data was extracted from gridded data and interpolated to $10 \mathrm{~km}$.

transform, trends in the data have to be removed, and tapering functions need to be applied at the edges. Moreover, the physical meaning of the semivariance is easy to interpret. In the case of mesoscale variability in the ocean, it represents the amplitude of the differences, and like eddy kinetic energy, high values represent regions with high mesoscale variability. The major advantage of the variogram, is that it is easy to calculate, requiring only a few lines of code.

These results confirm that the variogram indeed provides an indication of the size of mesoscale features for a given region, and in addition to this is able to determine the presence of periodic signals, as well as comparable magnitudes of the variance.

\subsubsection{Quantifying spatial scales of mesoscale variability}

To quantify the spatial scale of mesoscale variability in key regions of the greater Agulhas Current system, three sections were defined along which SLA data from Aviso, HYCOM $\mathrm{O} 2$ and HYCOM O4 was extracted (see Figs. 8 and 9).

The Mozambique Channel section, extending southward from $43^{\circ} \mathrm{E} / 14^{\circ} \mathrm{S}$ to $30^{\circ} \mathrm{E} / 33.5^{\circ} \mathrm{S}$, was chosen to represent the path along which predominantly anticyclonic eddies propagate southward from the Mozambique Channel toward the northern Agulhas Current. This path can be clearly identified in both HYCOM O2 and $\mathrm{O} 4$ simulations, and is also evident in the altimetry field.

The Aviso SLA experimental variogram (Fig. 11a, left) was fitted with a Gaussian function (the first term in Eq. 5), indicating that a maximum variance (or sill) of $355 \mathrm{~cm}^{2}$ is reached at a radius (or range) of $150 \mathrm{~km}$. This suggests that mesoscale features (eddies or meanders) along this section have diameters up to $375 \mathrm{~km}$, somewhat larger than previously documented.

As discussed previously (Sect. 4.3.1), the HYCOM O2 variogram (Fig. 11, middle) was fitted with a curve combining a Gaussian and cosine function (Eq. 5). The respective Gaussian and cosine ranges, $\left(a_{g}\right.$ and $\left.a_{c}\right)$ indicate that, contrary to previous findings (Backeberg et al., 2008), the Mozambique Channel eddies in HYCOM O2 are smaller and less intense than in reality, with diameters of $275 \mathrm{~km}$, and a semivariance $60 \%$ less than observed from altimetry. In addition to this the periodicity, with successive eddies $\sim 560 \mathrm{~km}$ $\left(a_{c} \times 2 \pi\right)$ apart, is not evident in the altimetry SLA section, indicating that the formation of eddies in the $\mathrm{O} 2$ simulation is too regular/periodic.

Applying the 4th order advection scheme in HYCOM improves some of the deficiencies of the $\mathrm{O} 2$ scheme in the Mozambique Channel. The amplitude of the Gaussian sill $\left(C_{g}\right)$ is much higher, and the range has increased to $140 \mathrm{~km}$, corresponding to a diameter of $350 \mathrm{~km}$, in better agreement with the altimetry observations. There is also some improvement in the (artificial) periodicity, in that the amplitude of the cosine function $\left(C_{c}\right)$ is slightly lower, suggesting a reduction of the periodicity.

The second section extends from $32^{\circ} \mathrm{E} / 30^{\circ} \mathrm{S}$ along the South African east coast toward the retroflection region at $20^{\circ} \mathrm{E} / 39^{\circ} \mathrm{S}$ and lies within a band of negative skewness thought to be associated with periodic cyclonic disturbances or Natal Pulses.

The Aviso variogram analysis, with $C_{c}=220 \mathrm{~cm}^{2}$ and $a_{c}=125 \mathrm{~km}$, here indicates mesoscale diameters of up to $312.5 \mathrm{~km}$, in agreement with the documented scale of the Agulhas retroflection loop (340 km; Lutjeharms and van Ballegooyen, 1988).

The amplitude of the sill in $\mathrm{O} 2$ is much higher $\left(C_{c}=450 \mathrm{~cm}^{2}\right)$, with a shorter range $\left(a_{g}=100 \mathrm{~km}\right)$ corresponding to diameters of $250 \mathrm{~km}$. A periodicity of $80 \mathrm{~km}$ (corresponding to eddies $\sim 500 \mathrm{~km}$ apart) confirms the successive train of eddies simulated in $\mathrm{O} 2$.

The HYCOM O4 variogram is in much better agreement with the altimetry, and no periodicity is evident. A Gaussian function provides the theoretical fit. The amplitude of the sill is slightly higher, but the range of $125 \mathrm{~km}$ is in good agreement with the altimetry. A train of eddies (as in O2) will 

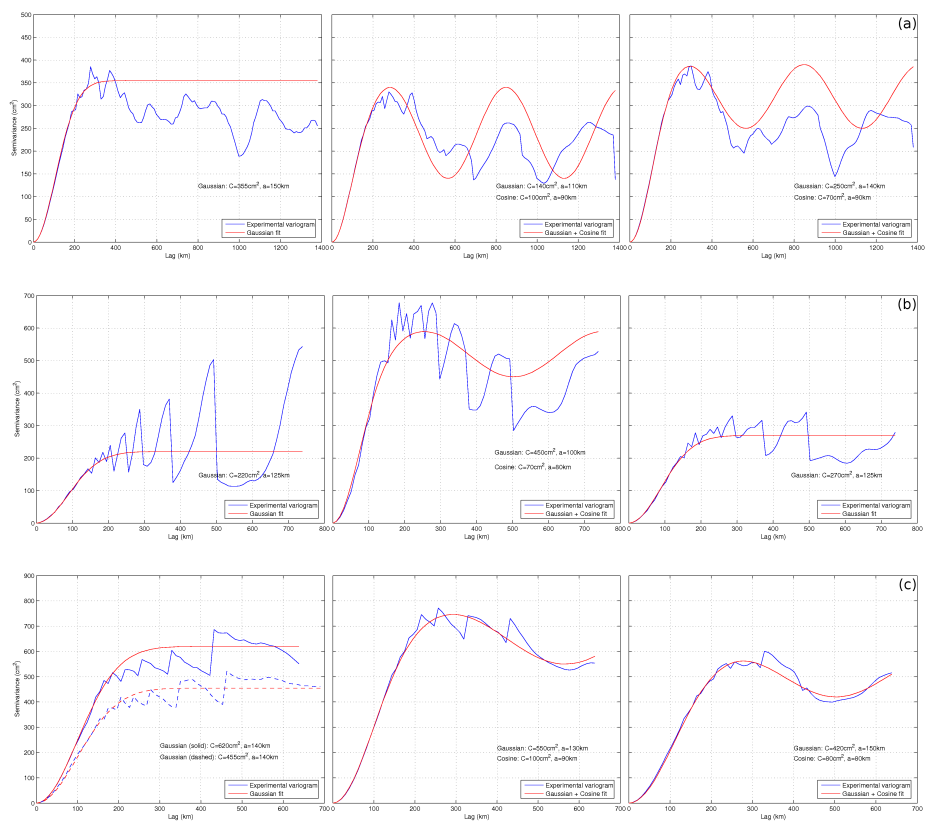

Fig. 11. Variogram analysis for Aviso (left column), HYCOM O2 (middle column) and HYCOM O4 (right column). SLA data was extracted from gridded data along sections for the Mozambique Channel (a), Agulhas Current (b) and Agulhas Ring shedding corridor (c) and interpolated to $10 \mathrm{~km}$. See straight black lines in Figs. 8a and 9.

result in a variogram with a higher variance at the sill, due to the enhanced variability associated with an eddy field, but with a smaller spatial scale compared to a well defined current extending southwestward with a large retroflection loop at its termination, as in Aviso and O4. This result presents an additional indication that the $\mathrm{O} 4$ scheme provides a much more realistic simulation of the southern Agulhas Current.

From the skewness analysis two sections were defined in the altimetry for the northwestward passage of Agulhas Rings. The first (solid line, Fig. 11c, left) corresponding to the track along which rings seem to preferentially propagate in HYCOM (Fig. 9) and the second where according to the skewness field from altimetry (Fig. 8), predominantly anticyclonic eddies are found in the observations (dashed line).

The Aviso variogram shows that the northern section has a variance of $620 \mathrm{~cm}^{2}$, with a scale of $140 \mathrm{~km}$, corresponding to diameters of $350 \mathrm{~km}$. The variance in the southern section is $40 \%$ lower, but the length scales are similar $(135 \mathrm{~km}$ corresponding to a diameter of $337.5 \mathrm{~km}$ ). This indicates, that eddies shed from the retroflection tend to preferentially propagate along the northern track, and that the altimetry skewness field is unable to indicate this path as pointed out by Thompson and Demirov (2006). Note that Agulhas Rings have been documented to have diameters of up to $320 \mathrm{~km}$ (Lutjeharms and van Ballegooyen, 1988), in good agreement with the variogram analysis.

While in both model simulations the spatial scales are in good agreement with the altimetry observations, the ampli- tude of the variance in $\mathrm{O} 2$ is too large. A periodic (cosine) signal is also evident in both simulations, suggesting an artificial regularity of Agulhas Ring shedding. This amplitude is somewhat lower in the $\mathrm{O} 4$ scheme.

In conclusion, using the variogram tool, the spatial scales of mesoscale features for three sections in the greater Agulhas Current system were quantified. In addition to this, the variogram analysis, provides an objective tool for comparing and validating the two model simulations. It was able to identify (unrealistic) periodic signals in the model simulations, as well as provide a good quantitative comparison of the scales of the ocean features. A major improvement of the $\mathrm{O} 4$ simulation is that the periodicity evident in all the sections for the $\mathrm{O} 2$ scheme, is reduced in the Mozambique Channel and ring shedding corridor, and significantly, absent for the section through the Agulhas Current. Moreover, the spatial scales and amplitudes of the variances in HYCOM using the 4th order advection scheme are much more realistic, and in better agreement with the altimetry observations.

\section{Conclusions}

From this inter-comparison of the two numerical advection schemes in HYCOM it was clearly shown that applying higher order numerics (the 4 th order momentum advection scheme) significantly improve the model simulation of the greater Agulhas Current regime. 
The most significant improvement in the $\mathrm{O} 4$ simulation is the change in the southern Agulhas Current, from a train of successive eddies, to a well-defined meandering current. Stronger poleward transports and a much improved vertical structure of the Agulhas Current near $32^{\circ} \mathrm{S}$ in HYCOM O4 is evident. These improvements may contribute toward a better southwestward penetration of the temperature field, and implies a stronger leakage of warm, saline Indian Ocean waters into the South Atlantic Ocean vital for the Meridional Overturning Circulation.

Satellite altimetry measurements of the sea surface are used in model validation techniques. The sea surface height variations, sea level skewness and variogram analyses quantify the improvements evident in the simulation, as well as providing some new perspectives in terms of studying mesoscale variability in the ocean.

Sea level skewness was shown to be an ideal tool for studying flows with meanders that become unstable and change into eddies. In an eddy field it is able to distinguish between a preference for cyclonic or anticyclonic rotation. The zero skewness line in the southern Agulhas Current confirms that throughout the $\mathrm{O} 4$ model simulation, the current is represented as a well defined meandering current.

The variogram analysis confirms that the $\mathrm{O} 4$ scheme simulates more realistic scales and variances of mesoscale features. Additionally, it is able to identify (unrealistic) periodic signals such as too regular Mozambique Channel eddies and successive eddies in the southern Agulhas Current, which are pronounced deficiencies of the $\mathrm{O} 2$ scheme.

Finally, the Agulhas Current transport, and hence the IndoAtlantic inter-ocean exchange, is sensitive to mesoscale features that originate upstream in the source regions. HYCOM O4, in particular with the improved simulation of the southern Agulhas Current, is well suited for application in further studies of this exchange.

Acknowledgements. We would like to thank the team at the Mohn-Sverdrup Center for their technical support, in particular for the implementation of the higher order advection scheme in AGULHAS HYCOM. We would also like to acknowledge the reviewers for their cunstructive review of our work, in particular for suggesting the inclusion of a vorticity analysis. This work has been supported by the Mohn-Sverdrup Center for Global Ocean Studies and Operational Oceanography, through a private donation from Trond Mohn C/O Frank Mohn AS, Bergen, Norway, and a grant for CPU time from the Norwegian Super-computing (NOTUR) project. We gratefully acknowledge funding from the National Research Foundation of South Africa. L. Bertino and J. A. Johannessen acknowledge partial funding from the MERSEA integrated project (number SIP-CT-2003-502885) from the European Commission. We extend our kind thanks to H. L. Bryden for providing the gridded data from the Agulhas Current mooring (Fig. 5b). We are also grateful for the data supply from CNES, Remote Sensing Systems and NOAA/OAR/ESRL PSD.

Edited by: E. J. M. Delhez

\section{References}

Backeberg, B. C., Johannessen, J. A., Bertino, L., and Reason, C. J.: The greater Agulhas Current system: An integrated study of its mesoscale variability, Journal of Operational Oceanography, 1(1), 29-44, 2008.

Barnier, B., Madec, M., Pendruff, T., Molines, J.-M., Treguier, A.M., Sommer, J. L., Beckmann, A., Biastoch, A., Bnning, C., Dengg, J., Derval, C., Durand, E., Gulev, S., Remy, E., Talandier, C., Theetten, S., Maltrud, M., McClean, J., and DeCuevas, B.: Impact of partial steps and momentum advection schemes in a global ocean circulation model at eddy permitting resolution, Ocean Dynam., 56(5-6), 543-567, 2006.

Bentsen, M., Evensen, G., Drange, H., and Jenkins, A. D.: Coordinate transformation on a sphere using conformal mapping, Mon. Weather Rev., 127, 2733-2740, 1999.

Biastoch, A. and Krauss, W.: The role of mesoscale eddies in the source regions of the Agulhas Current, J. Phys. Oceanogr., 29, 2303-2317, 1999.

Bleck, R.: An oceanic general circulation model framed in hybrid isopycnic-Cartesian coordinates, Ocean Model., 37, 55-88, 2002.

Bleck, R.: On the use of hybrid vertical coordinates in ocean circulation modeling, in: Ocean Weather Forecasting, edited by: Chassignet, E. P. and Verron, J., Springer, Netherlands, 109-126, 2006.

Bleck, R. and Smith, L.: A wind-driven isopycnic coordinate model of the North Atlantic and Equatorial Atlantic Ocean. 1: Model development and supporting experiments, J. Geophys. Res., 95, 3273-3285, 1990.

Boebel, O., Rossby, T., Lutjeharms, J. R. E., Zenk, W., and Barron, C.: Path and variability of the Agulhas Return Current, Deep-Sea Res. (II Top. Stud. Oceanogr.), 50, 35-56, 2003.

Leonard, B. P.: A stable and accurate convective modelling procedure based on quadratic upstream interpolation, Comp. Methods Appl. Mech. Eng., 19, 59-98, 1979.

Browning, G. L. and Kreiss, H. O.: Initialization of the shallow water equations with open boundaries by the bounded derivative method, Tellus, 34, 334-351, 1982.

Browning, G. L. and Kreiss, H. O.: Scaling and computation of smooth atmospheric motions, Tellus A, 38, 295-313, 1986.

Bryden, H. L., Beal, L. M., and Duncan, L. M.: Structure and Transport of the Agulhas Current and Its Temporal Variability, J. Oceanogr., 61, 479-492, 2005.

Bryden et al., Bacon, S., Beal, L. M., Bonner, R. N., et al.: Agulhas Current Experiment, Cruise Report No. 249, Institute of Oceanographic Sciences, Wormley, 85 pp., 1995.

Davies, H. C.: Limitations of some common lateral boundary schemes used in NWP models, Mon. Weather Rev., 111, 10021012, 1983.

de Ruijter, W. P. M., Ridderinkhof, H., Lutjeharms, J. R. E., Schouten, M. W., and Veth, C.: Observations of the flow in the Mozambique Channel, Geophys. Res. Lett., 29(10), 1502-1504, 2002.

de Ruijter, W. P. M., van Leeuwen, P. J., and Lutjeharms, J. R. E.: Generation and Evolution of Natal Pulses: Solitary Meanders in the Agulhas Current, J. Phys. Oceanogr., 29, 3043-3055, 1999.

Gneiting, T., Sasvári, Z., and Schlather, M.: Analogies and correspondences between variograms and covariance functions, Adv. Appl. Prob., 33, 617-630, 2001. 
Gründlingh, M. L.: On the course of the Agulhas Current, S. Afr. Geograph. J., 65, 49-57, 1983.

Le Traon, P.-Y.: Satellite oceanography for ocean forecasting, in: Ocean Forecasting, edited by: Pinardi, N. and Woods, J. D., Springer, New York, USA, 19-36, 2002.

Legates, D. and Willmott, C.: Mean seasonal and spatial variability in gauge-corrected, global precipitation, J. Clim., 10, 111-127, 1990.

Lutjeharms, J. R. E. and Roberts, H. R.: The Natal Pulse: An extreme transient on the Agulhas Current, J. Geophys. Res., 93, 631-645, 1988.

Lutjeharms, J. R. E. and Valentine, H. R.: Southern Ocean thermal fronts south of Africa, Deep-Sea Res., 31(12), 1461-1475, 1984.

Lutjeharms, J. R. E. and van Ballegooyen, R. C.: The retroflection of the Agulhas Current, J. Phys. Oceanogr., 18, 1570-1583, 1988.

Matano, R. P. and Beier, E. J.: A kinematic analysis of the Indian/Atlantic interocean exchange, Deep-Sea Res. Pt. II , 50, 229-249, 2003.

Morel, Y., Darr, D., and Tailandier, C.: The stability of coastal upwelling and downwelling currents, J. Phys. Oceanogr., 36, 875896,2006

Reynolds, R. W. (1988): A real-time global sea surface temperature analysis, J. Climate, 1, 75-86, 1988.

Reynolds, R. W. and Marsico, D. C.: An improved real-time global sea surface temperature analysis, J. Climate, 7, 929-948, 1994.

Reynolds, R. W., Rayner, N. A., Smith, T. M., Stokes, D. C., and Wang, W.: An improved in situ and satellite sst analysis for climate, J. Climate, 15, 1609-1625, 2002.

Richardson, P. L. and Garzoli, S. L.: Characteristics of intermediate water flow in the Benguela current as measured with RAFOS floats, Deep-Sea Res. Pt. II, 50, 87-118 2003.

Rio, M.-H., and Hernandez, F.: A mean dynamic topography computed over the world ocean from altimetry, in situ measurements, and a geoid model, J. Geophys. Res., 109, C12032, doi:10.1029/2003JC002226, 2004.

Rio, M.-H., Schaeffer, P., Lemoine, J.-M., and Hernandez, F.: Estimation of the ocean mean dynamic topography through the combination of altimetric data, in situ measurements and grace geoid, in Proceedings of the GOCINA international workshop, Luxembourg, 2005.

Rouault, M. and Lutjeharms, J. R. E.: Estimation of sea-surface temperature around southern Africa from satellite-derived microwave observations, S. Afr. J. Sci., 99, 489-494, 2003.
Sætre, R. and da Silva, A. J.: The circulation of the Mozambique Channel, Deep-Sea Res., 31, 485-508, 1984.

Sanderson, B. G.: Order and resolution for computational ocean dynamics, J. Phys. Oceanogr., 28, 1271-1286, 1998.

Schouten, M. W., de Ruijter, W. P. M., and van Leeuwen, P. J.: Upstream control of Agulhas Ring shedding, J. Geophys. Res., 107(C8), 3109-3120, 2002.

Siedler, G., Rouault, M., Biastoch A., Backeberg, B., Reason, C. J. C., and Lutjeharms J. R. E.: Modes of the southern extension of the East Madagascar Current, J. Geophys. Res., 114, C01005, doi:10.1029/2008JC004921, 2009.

Slutz, R., Hiscox, S. L. J., Woodruff, S., Jenne, R., Joseph, D., Steurer, P., and Elms, J.: Comprehensive ocean-atmosphere dataset, Release 1. Tech. Rep. NTIS PB86-105723, NOAA Environmental Research Laboratories, Climate Research Program, Boulder, CO, 1985.

Teague, W. J., Carron, M., and Hogan, P. J.: A comparison between the Generalized Digital Environmental Model and Levitus climatologies, J. Geophys. Res., 95(C5), 7167-7183, 1990.

Thompson, K. R. and Demirov, E.: Skewness of sea level variability of the world's oceans, J. Geophys. Res., 111(C05005), doi:10.1029/2004JC002839, 2006.

Treguier, A. M., Boebel, O., Barnier, B., and Madec, G.: Agulhas eddy fluxes in a $1 / 6^{\circ}$ Atlantic model, Deep-Sea Res. Pt. II, 50, 251-280, 2003.

Uppala, S. M., Kållberg, P. W., Simmons, A. J., Andrae, U., Da Costa Bechtold, V., Fiorino, M., Gibson, J. K., Haseler, J., Hernandez, A., Kelly, G. A., Li, X., Onogi, K., Saarinen, S., Sokka, N., Allan, R. P., Andersson, E., Arpe, K., Balmaseda, M. A., Beljaars, A. C. M., Van De Berg, L., Bidlot, J., Bormann, N., Caires, S., Chevallier, F., Dethof, A., Dragosavac, M., Fisher, M., Fuentes, M., Hagemann, S., Hlm, E., Hoskins, B. J., Isaksen, L., Janssen, P. A. E. M., Jenne, R., McNally, A. P., Mahfouf, J.-F., Morcrette, J.-J., Rayner, N. A., Saunders, R. W., Simon, P., Sterl, A., Trenberth, K. E., Untch, A., Vasiljevic, D., Viterbo, P., and Woollen, J.: The ERA-40 re-analysis, Q. J. R. Meteorol. Soc., 131(612), 2961-3012, 2005.

Wackernagel, H.: Multivariate geostatistics: An Introduction with Applications, 2nd edn., Springer-Verlag Telos, Berlin, Germany, 291 pp., 1998.

Webb, D. J., Cuevas, B. A., and Richmond, C.: Improved advection schemes for ocean models, J. Atmos. Ocean Tech., 15, 11711187, 1998.

Winther, N. G., Morel, Y., and Evensen, G.: Effciency of high order numerical schemes for momentum advection, J. Mar. Sys., 67, 31-46, 2007. 